\title{
The Interaction Between Economic Level and Pipeline Logistics in China-Based on Vector Error Correction Model
}

\author{
Zhi-wang Qian, Yufeng Shi \\ Shanghai University of Medicine \& Health Sciences, Shanghai, China
}

\begin{abstract}
The interaction between the economic level and the pipeline logistics is analyzed by using the Granger causality test, error correction model, and impulse response analysis in this paper. The results show that the level of economic development will support pipeline logistics, but the level of pipeline logistics will not support the economic development obviously.
\end{abstract}

Keywords: economic level, pipeline logistics, error correction model, impulse response analysis

\section{Introduction}

With the "13th Five-Year" planning and "The Belt and Road" strategy, logistics industry has got the new opportunities in China. As the third source of profit, logistics has always been the interest of many people. Many scholars pay attention to this field, mainly in the road, railway, water, and aviation logistics. While there are few related researches on pipeline logistics. Since 1990s, with the rapid growth of Chinese GDP, the volume of freight traffic is rising year by year. Statistics show that the GDP increased from 1,877,430 million in 1990 to $63,613,870$ million in 2014 , the pipeline mileage also increased from $15,900 \mathrm{~km}$ to $105,700 \mathrm{~km}$, the freight volume of pipeline increased from 157,500 thousand in 1990 to 737,520 thousand tons in 2014, the average annual growth rate is $6.92 \%$. There is an internal relationship between the pipeline logistics, the total pipeline mileage and GDP (Zhong, 2009).

We select the time series data from 1990 to 2014 to carry out unit root test, cointegration test, Grainger causality test, vector error correction model (VECM), impulse response analysis (IRF) to study the dynamic relationship between the freight volume of pipeline and GDP, pipeline mileage. The article uses Eviews 8.0 statistical software for analysis.

\section{Literature Review}

The relationship between economic level and logistics level has always been a hot topic; many scholars at home and abroad have studied the relationship between them.

In China, Liu (2012) studied the relationship between logistics and regional economic growth based on self-vector regression model, he found that the logistics industry is a new industry to stimulate economic

Zhi-wang Qian, professor, School of Information and Management, Shanghai University of Medicine \& Health Sciences, Shanghai, China.

Yufeng Shi, associate professor, School of Information and Management, Shanghai University of Medicine \& Health Sciences, Shanghai, China.

Correspondence concerning this article should be addressed to Yufeng Shi, School of Information and Management, Shanghai University of Medicine \& Health Sciences, Shanghai 201318, China. 
growth, and economic growth will stimulate logistics in reverse (Liu, 2012). Lu (2016) uses cointegration model to get a long-term equilibrium relationship between regional logistics industry and regional economy. Xu and Huang (2011) studied the regional logistics and regional economy in Zhejiang province, and found that the regional economy was the foundation of regional logistics; regional logistics and regional economic development are interdependent and mutually supported.

Kuzu and Onder (2014) studied the long-term relationship between logistics development and economic growth in Turkey, pointed out that there was a cointegration relationship between logistics and economy; economy was the Grainger reason of logistics, and played an important role in the development of logistics. Marazzo, Scherre, and Fernandes (2010) conducted an empirical research on air traffic and economic growth in Brazil for nearly 40 years, and found that there was a long-term equilibrium relationship between them; the impulse response analysis indicated that GDP changes affected the air traffic.

The domestic and foreign literatures were mainly concentrated on two aspects: one was the relationship between regional logistics and regional economy; the other was the relationship between the level of logistics represented by traditional transportation and economic growth. Pipeline logistics has not been the focus of attention of scholars at home and abroad, there are few literatures on the relationship between pipeline logistics and economic growth.

\section{Model building and Data Selection}

\section{Johansen Cointegration Test}

Johansen cointegration test is a good method to test the multivariate cointegration relationship, which was put forward by Johansen in 1988. It’s based on VAR model (Johansen, 1988).

In VAR model, we set variables including $\mathrm{y}_{1 \mathrm{t}}, \mathrm{y}_{2 \mathrm{t}}, \ldots, \mathrm{y}_{\mathrm{kt}}$ as non-stationary first-order sequence, then $\mathrm{y}_{t} \sim \mathrm{I}(1) . \mathrm{x}_{1 t}$ is a dimensional exogenous vector, representing the trend term, constant term, etc.

$$
y_{t}=A_{1} y_{t-1}+A_{2} y_{t-2}+\cdots+A_{p} y_{t-p}+B x_{t}+\mu_{t}(t=1,2, \cdots, n)
$$

The first-order sequence of $\mathrm{y}_{1 \mathrm{t}}, \mathrm{y}_{2 \mathrm{t}}, \ldots, \mathrm{y}_{\mathrm{kt}}$ is changed to zero-order sequence $\mathrm{I}(0)$, as follows.

$$
\begin{gathered}
\Delta y_{t}=\Pi y_{t-1}+\sum_{i=1}^{p-1} \Gamma_{i} y_{t-1}+\mathrm{B} x_{t}+\mu_{t} \\
\Pi=\sum_{i=1}^{p} \mathrm{~A}_{i}-\mathrm{I} \\
\Gamma_{i}=-\sum_{i=1}^{p} \mathrm{~A}_{j}
\end{gathered}
$$

Among them, $\Delta y_{t}$ and $y_{t-\mathrm{j}}(j=1,2, \cdots, p)$ are all vector variables in $\mathrm{I}(0)$. If $\Pi y_{t-1}$ is also a vector in $\mathrm{I}(0)$, then there is cointegration relationship between $\mathrm{y}_{1 \mathrm{t}-1}, \mathrm{y}_{2 \mathrm{t}-1}, \ldots, \mathrm{y}_{\mathrm{kt}-1}$ and $\Delta y_{t}$ is stable.

\section{Vector Error Correction (VEC) Model}

Vector error correction (VEC) model is a vector autoregressive (VAR) model with cointegration constraints. VEC model can be constructed only when there is a cointegration relationship among variables.

The mathematical expression of VEC model is as follows: 


$$
\Delta y_{t}=\alpha \beta^{\prime} y_{t-1}+\sum_{i=1}^{p-1} \Gamma_{i} y_{t-1}+\mu_{t}(t=1,2, \cdots, n)
$$

Among them, the error term in each equation is smooth. The formula can be expressed as follows:

$$
\Delta y_{t}=\alpha e c m_{t-1}+\sum_{i=1}^{p-1} \Gamma_{i} y_{t-1}+\mu_{t}(t=1,2, \cdots, n)
$$

The obtained equation is the error correction model, ecm $m_{t-1}=\beta^{\prime} y_{t-1}$ is error correction, which can reflect the long-term equilibrium relationship between variables. The coefficient of variance $\alpha$ can adjust the equilibrium relation between variables deviates to the equilibrium state. The coefficient of variance difference on the right side of the error correction model reflects the influence of short-term fluctuation of each variable on the short-term variation of the explanatory variables.

\section{Data Selection}

We select annual data from 1990 to 2014 to conduct empirical research, all the data come from China Statistical Yearbook of 2015. Pipeline logistics is represented by freight volume of pipeline (HYL), the economic level is represented by GDP, and infrastructure construction is represented by pipeline mileage (LCS). Statistics data description is shown in Table 1.

Table 1

Statistics Data Description

\begin{tabular}{llll}
\hline Statistics data & GDP (billion yuan) & HYL (million tons) & LCS (million kilometers) \\
\hline Mean value & $30,711.20$ & $206,100.50$ & 4.28 \\
Maximum value & $73,752.00$ & $636,138.70$ & 10.57 \\
Minimal value & $14,783.00$ & $18,774.30$ & 1.59 \\
Standard deviation & $18,519.15$ & $189,938.90$ & 2.90 \\
& $\mathrm{~N}$ & $25 \times 3=75$ & \\
\hline
\end{tabular}

\section{Empirical Research Results and Analysis}

The data trend can be linearized and the heteroscedasticity in time series can be eliminated by natural logarithm transformation. Therefore, in this paper, we take first difference of LnHYL, LnGDP, LnLCS, the difference of the data is shown in Figure 2.

Figure 1 shows that the data are on the rise trend, and it is a non-stationary time series data. Figure 2 shows that the data may be the first order sequence. The article uses ADF test, test results are shown in Table 2.

Table 2 shows that the variables including LnHYL, LnGDP, LnLCS will accept the original assumption of the existence of unit roots, at the significance level of 5\%, so LnHYL, LnGDP, LnLCS sequences data are not stable. Variables like D(LnHYL), D(LnGDP), D(LnLCS), reject the original assumption of unit roots, so the first difference variables are stable. Therefore, LnHYL, LnGDP, LnLCS are I(1) sequence. There is cointegration relationship between them. In this paper, Johansen cointegration test is used to test whether there is a cointegration relationship between three variables.

The results of Tables 3 and 4 indicate that there's a cointegration relationship between three sets of data, and there are two cointegration vectors. According to the results, we make further analysis of these three sets of data by VECM. 


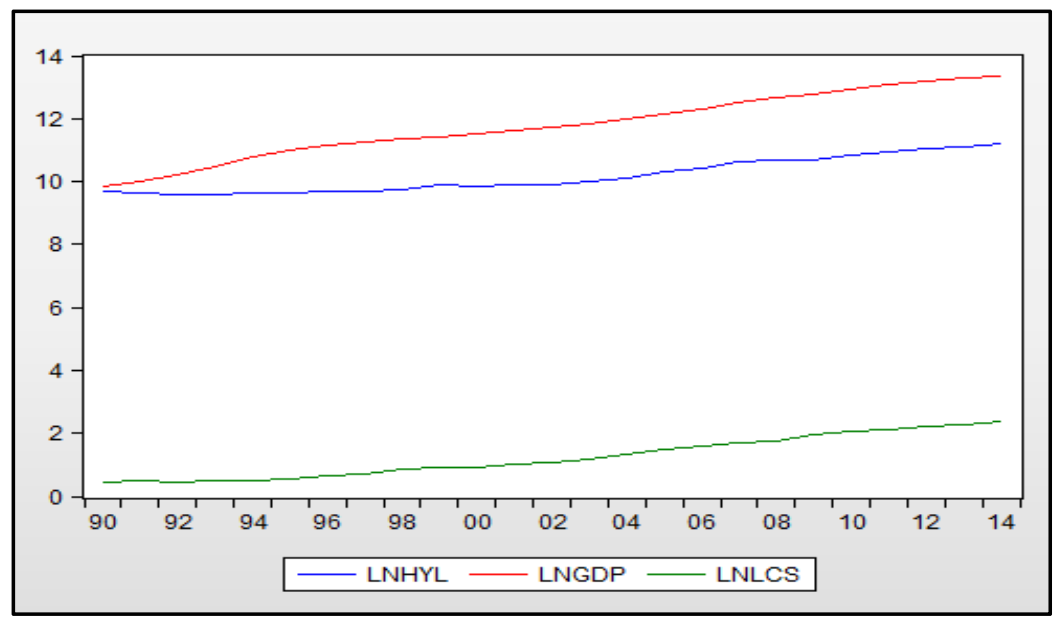

Figure 1. Time sequence diagram of LnHYL, LnGDP, LnLCS.

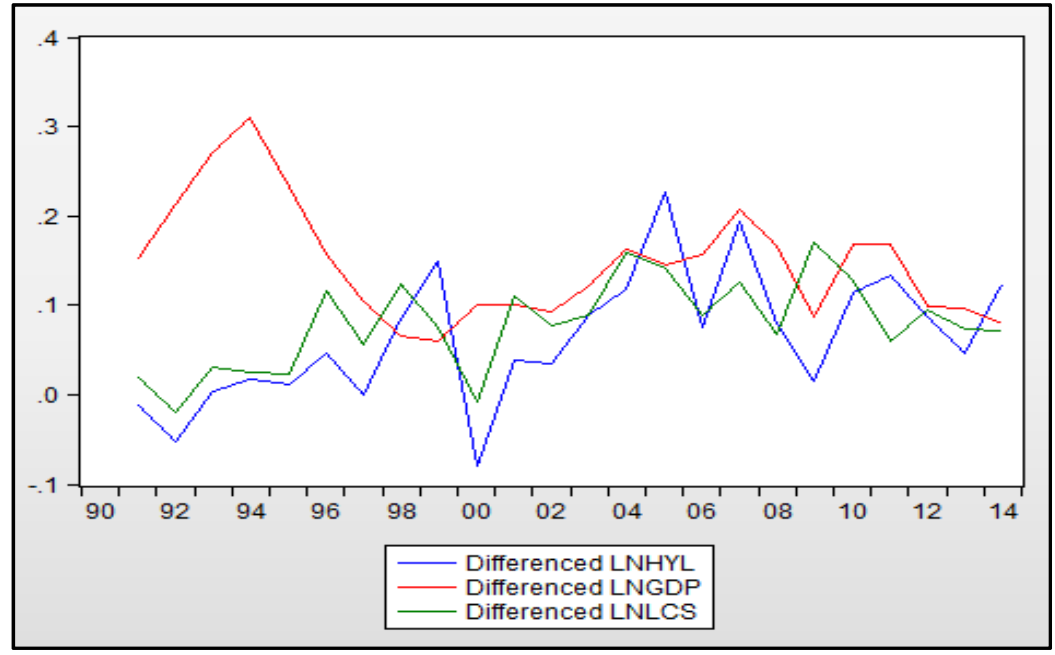

Figure 2. Time sequence diagram of D(LnHYL), D(LnGDP), D(LnLCS).

Table 2

Results of Stationary Test of Unit Root

\begin{tabular}{llllll}
\hline Variable & ADF value & Critical value of 5\% & Test type & $P$ value & Conclusion \\
\hline LnHYL & -2.1612 & -3.6122 & CT0 & 0.4882 & Unstable \\
D(LnHYL) & -4.5443 & -3.6220 & CT0 & 0.0076 & Stable \\
LnGDP & -2.9870 & -3.6736 & CT5 & 0.1607 & Unstable \\
D(LnGDP) & -4.3686 & -3.6584 & CT3 & 0.0129 & Stable \\
LnLCS & -3.0775 & -3.6122 & CT0 & 0.1338 & Unstable \\
D(LnLCS $)$ & -3.9725 & -3.6220 & CT0 & 0.0250 & Stable \\
\hline
\end{tabular}

Table 3

Johansen Cointegration Test-Trace Test Result

\begin{tabular}{lllll}
\hline Number of association & Characteristic value & Trace test value & 5\% Critical value & $P$ value \\
\hline None* & 0.6715 & 43.3251 & 29.7971 & 0.0008 \\
At most $1 *$ & 0.5367 & 17.7180 & 15.4947 & 0.0228 \\
At most 2 & 0.0010 & 0.0223 & 3.8415 & 0.8813 \\
\hline
\end{tabular}

Note. * means the $p$ value of it passed the test. 
Table 4

Johansen Co Integration Test-Maximum Eigenvalue Test

\begin{tabular}{lllll}
\hline Number of association & Characteristic value & Maximum eigenvalue & 5\% Critical value & $P$ value \\
\hline None* & 0.6715 & 25.6071 & 21.1316 & 0.0109 \\
At most $1^{*}$ & 0.5367 & 17.6957 & 14.2646 & 0.0138 \\
At most 2 & 0.0010 & 0.0223 & 3.8415 & 0.8813 \\
\hline
\end{tabular}

Note. ${ }^{*}$ means the $p$ value of it passed the test.

\section{Grainger Causality Test}

Results of cointegration test show that there is a long-term stable equilibrium relationship between the level of pipeline, logistics, and economic development, and whether this equilibrium relationship from the causal relation needs to be verified. In this paper, according to the principle of Granger causality test, we set the lag period as two, and take Granger causality test for LnHYL, LnGDP, and LnLCS. Test results are shown in Table 5.

Table 5

Grainger Causality Test Results

\begin{tabular}{|c|c|c|c|}
\hline Original hypothesis & $F$ value & $P$ value & Result \\
\hline LnGDP is not Granger reason of LnHYL & 3.1374 & 0.0678 & Accept \\
\hline LnHYL is not Granger reason of LnGDP & 2.4906 & 0.1109 & Reject \\
\hline LnLCS is not Granger reason of LnHYL & 8.1960 & 0.0029 & Reject \\
\hline LnHYL is not Granger reason of LnLCS & 3.5903 & 0.0486 & Reject \\
\hline LnLCS is not Granger reason of LnGDP & 7.7530 & 0.0037 & Reject \\
\hline LnGDP is not Granger reason of LnLCS & 3.9039 & 0.0391 & Reject \\
\hline
\end{tabular}

As for interaction between GDP and pipeline logistics, at 10\% confidence level, it's believed that GDP is the Grainger reason of pipeline logistics. It may be considered that, the increase of GDP caused by oil and natural gas, coal and other energy consumption will stimulate the rise of pipeline logistics. However, the pipeline logistics is not the Grainger reason for GDP, its contribution for the promotion of economic growth is not obvious.

As for interaction between infrastructure and pipeline logistics, at the 5\% significant level, the original hypotheses are all rejected. Therefore they are Grainger reasons for each other. This conclusion is consistent with common sense.

As for interaction between GDP and infrastructure impact, at 5\% confidence level, GDP is the Grainger reason of infrastructure, and infrastructure is also Grainger reason of GDP. GDP growth will promote the development of infrastructure, and as an investment, infrastructure construction will also stimulate economic growth.

\section{Establishment of VECM}

The cointegration test results show that there is a cointegration relationship among the variables. According to the characteristics of cointegration, the vector error correction model is established. The three order VECM with two cointegration vectors is established based on the choice of the lag order number as two.

$$
\Delta y_{t}=\alpha e c m_{t-1}+\Gamma_{1} y_{t-1}+\Gamma_{2} y_{t-2}+\mu_{t}
$$

$y_{t}$ is a set of three column vectors representing the three sets of data. 


$$
y_{t}=\left(\begin{array}{c}
\ln (H L Y) \\
\ln (G D P) \\
\ln (L C S)
\end{array}\right)
$$

The function includes the volume of freight, GDP, mileage increments, and they are all the logarithm value.

\section{Parameter Estimation and Validation of VECM}

Table 6

Parameter Estimation Results

\begin{tabular}{llll}
\hline Error correction & $\mathrm{D}($ LnHYL $)$ & $\mathrm{D}($ LnGDP $)$ & $\mathrm{D}(\mathrm{LnLCS})$ \\
\hline CointEq1 & -0.7423 & -0.2172 & -0.5657 \\
CointEq2 & {$[-2.2551]$} & {$[-1.1819]$} & {$[-2.6633]$} \\
& -0.0538 & -0.2634 & -0.0160 \\
D(LNHYL(-1)) & {$[-0.5334]$} & {$[-4.6762]$} & {$[0.2464]$} \\
& -0.2162 & -0.0665 & -0.0789 \\
D(LNHYL(-2)) & {$[-0.7317]$} & {$[-0.4032]$} & {$[-0.4137]$} \\
& 0.2407 & 0.1733 & 0.2820 \\
D(LNGDP(-1)) & {$[1.0881]$} & {$[1.4033]$} & {$[1.9752]$} \\
& 0.4727 & 0.6576 & -0.0240 \\
D(LNGDP(-2)) & {$[1.4011]$} & {$[3.4920]$} & {$[-0.1102]$} \\
& 0.0385 & -0.0273 & 0.4199 \\
D(LNLCS(-1)) & {$[0.1006]$} & {$[-0.1280]$} & {$[1.7005]$} \\
D(LOGLCS(-2)) & 0.4060 & 0.2009 & -0.2154 \\
C & {$[0.8245]$} & {$[0.7310]$} & {$[-0.6778]$} \\
& 0.1271 & -0.0397 & -0.0639 \\
ADJ. R ${ }^{2}$ & {$[0.3219]$} & {$[-0.1803]$} & {$[-0.2509]$} \\
\hline
\end{tabular}

Table 6 is the result of parameter estimation of VECM. The number in brackets below each estimate is its $t$ value. According to the results of parameter estimation, although some of the estimated values are not significant, on the whole, the estimated results are satisfactory, and the goodness of fit is better. For VECM, it is important to analyze the impulse response.

\section{Impulse Response Analysis}

Impulse response function analysis method can be used to describe an endogenous variable of errors caused by the impact of the reaction. Taking a standard deviation as the impact, the current values of endogenous will change. The following figure gives an image of some orthogonal impulse response functions.

In Figure 3, if GDP is given by a unit of positive impact, the utility of logistics pipeline will be accelerated, but it lasts only about two periods, and then followed by a period of negative influence, finally it will rise gradually and be stabilized, remained at about 0.02. It can be concluded that GDP growth will boost the level of pipeline logistics in the short term. With the rapid development of economy, the pipeline logistics industry of our country will encounter bottlenecks. The low technical conditions of pipeline equipment affect the development of the pipeline logistics. With the progress of science and technology, it gives positive effect. 


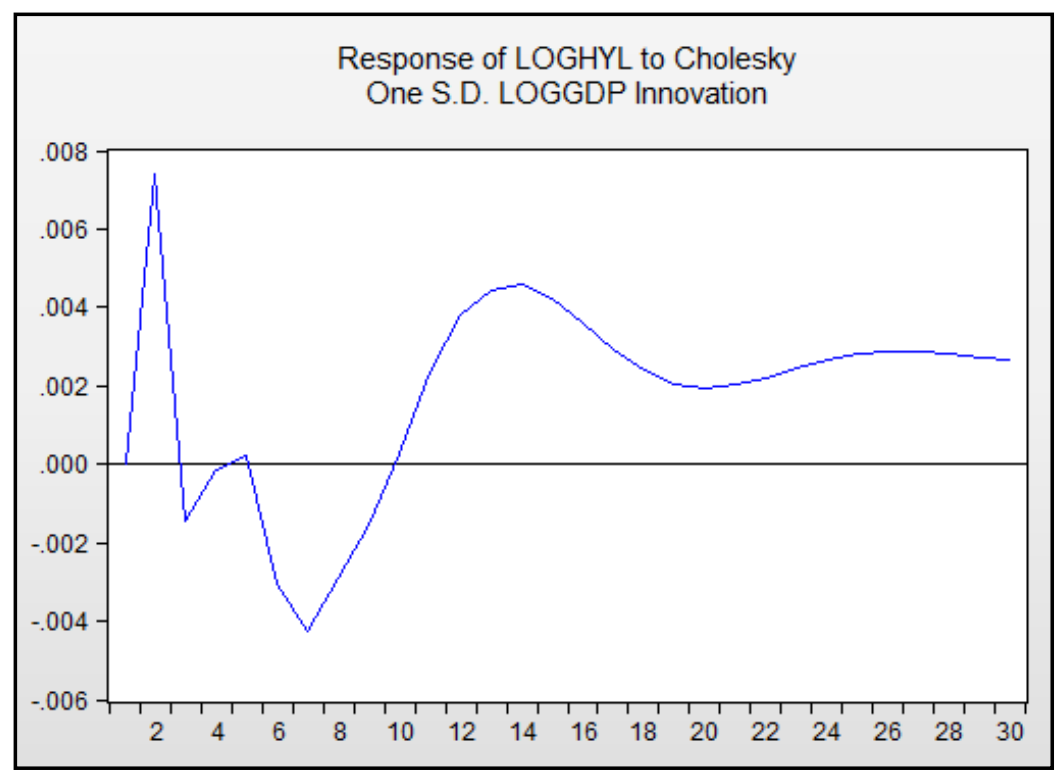

Figure 3. The impact of GDP on pipeline logistics.

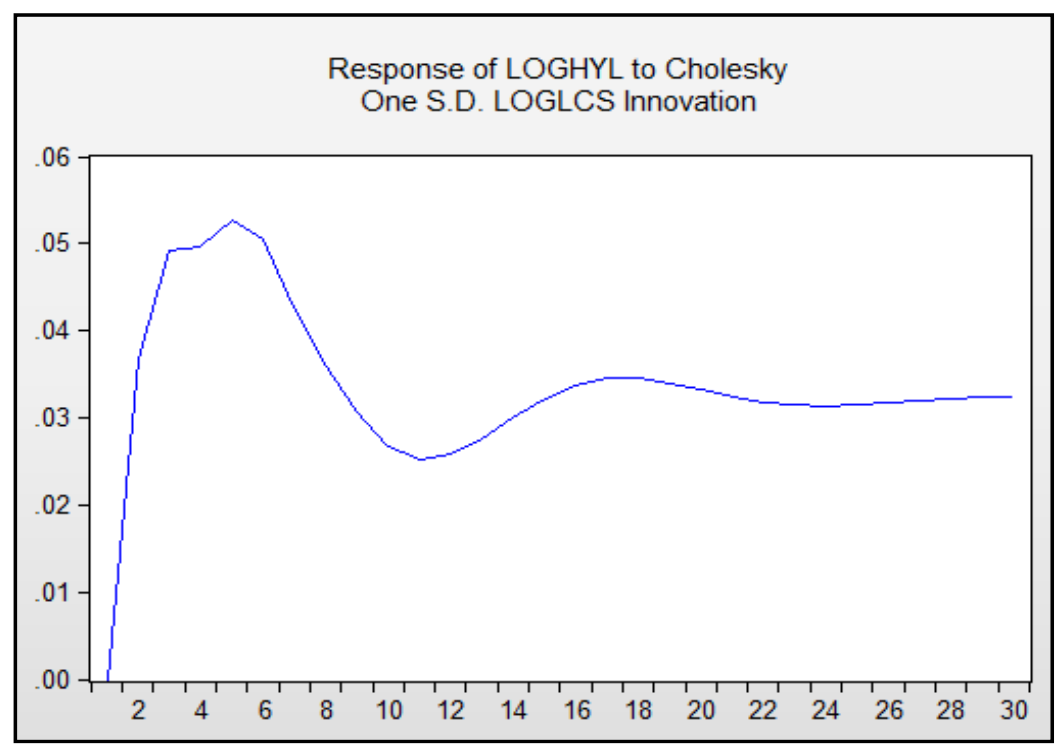

Figure 4. The impact of infrastructure on pipeline logistics.

Figure 4 shows the impact of infrastructure on the pipeline logistics. As we can see in the figure, from the beginning of the first phase, the role of pipeline logistics is accelerated. From the beginning of the fifth period, there's a decline, and it eventually stabilizes in the vicinity of 0.03 . The whole process is maintained above zero. The construction of infrastructure will promote the development of logistics industry, which is in line with our expectations.

Figure 5 shows that with a positive impact on the pipeline logistics, there will be a reduction in GDP. The whole process shows that pipeline logistics has a negative impact on GDP. There are some gaps between the theory and our expectations, but at present, the level of pipeline logistics in our country is still in the initial stage, the proportion of pipeline logistics in the total freight volume is small, and the growth effect is not significant. 


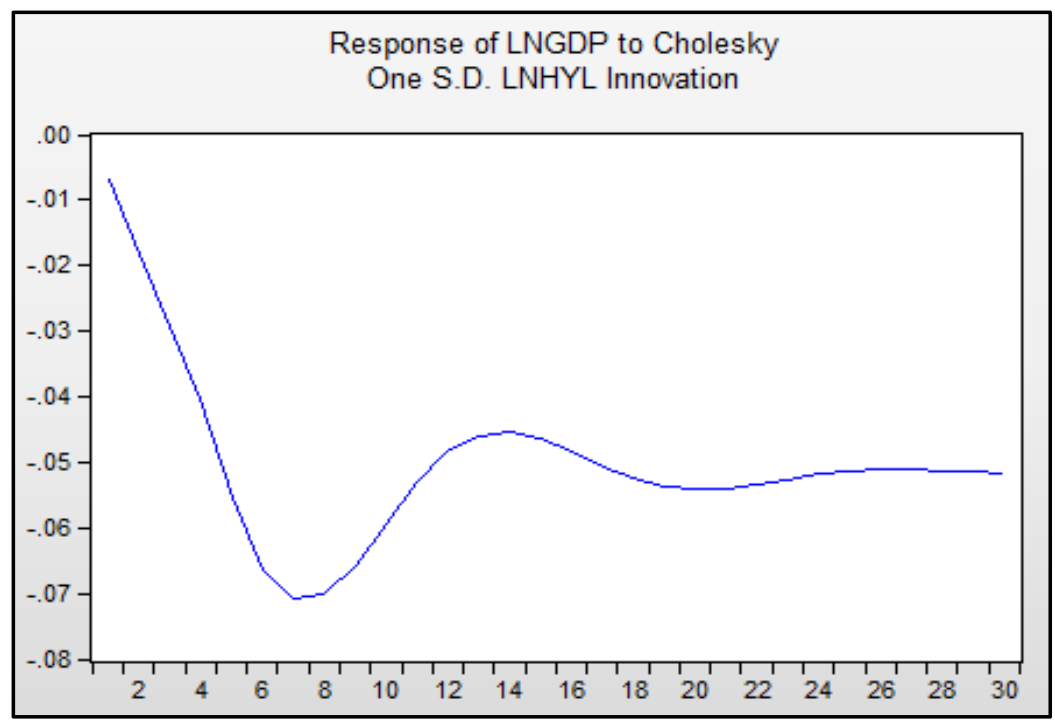

Figure 5. The impact of pipeline logistics on GDP.

\section{Conclusions}

In this paper, the stationary test is carried out, the three sets of data are all I(1). After further study on the cointegration situation, we get the conclusion that there are two cointegration vectors between them. And then we establish error correction model. Through the Grainger causality test, at $10 \%$ of significance level, GDP is the reason for the pipeline logistics, indicating that the impact of GDP on the pipeline logistics really exists, but the pipeline logistics has no significant impact on GDP. Grainger reason exists among other variables. It can be seen from the impulse response function that the level of GDP and infrastructure will promote the development of pipeline logistics. At present, pipeline transportation in China is in the initial stage, the proportion of investment in pipeline logistics is smaller than that of road and railway. In the "13th Five-Year" planning, with "The Belt and Road" strategy, we should make full use of pipeline to strengthen the pipeline infrastructure construction, and develop the foreign market.

\section{References}

Johansen, S. (1988). Statistical analysis of cointegration vectors. Journal of Economic Dynamics and Control, 12(2), $231-254$.

Kuzu, S., \& Önder E. (2014). Research into the long-run relationship between logistics development and economic growth in Turkey. Social Science Electronic Publishing, 3(1), 11-16.

Liu, P. (2012). Research on the relationship between regional logistics and economic growth based on VAR model. Logistics Technology, 31(13), 218-220.

Lu, J. H. (2016). Research on the relationship between logistics industry and regional economy: A case study of Changzhou. Logistics Technology, 35(1), 87-90.

Marazzo, M., Scherre, R., \& Fernandes, E. (2010). Air transport demand and economic growth in Brazil: A time series analysis. Transportation Research Part E Logistics \& Transportation Review, 46(2), 261-269.

Xu, Q., \& Huang, Z. Q. (2011). Study on the interaction between regional logistics and regional economic development: A case study of Zhejiang province. Statistics and Decision Making, 27(9), 116-119.

Zhong, X. J. (2009). Study on the relationship between foreign direct investments, import and export trade in China based on the impulse response function and variance decomposition method of VAR model. Statistical Education, 17(6), 14-20. 